https://www.journal-imab-bg.org

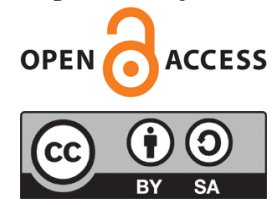

Original article

\title{
LONG-TERM AZITHROMYCIN TREATMENT IN CHRONIC OBSTRUCTIVE PULMONARY DISEASE
}

\author{
Vanya Kostadinova ${ }^{1}$, Yordan Radkov ${ }^{1}$, Temenuga Stoeva ${ }^{2}$, Darina Miteva ${ }^{1}$ \\ 1) Department of Pulmonary Diseases and Allergology, Medical University - \\ Varna, Bulgaria. \\ 2)Department of Microbiology and Virology, Medical University - Varna, \\ Bulgaria..
}

\section{SUMMARY}

Purpose: To assess the efficacy of Azithromycin on exacerbations in patients with chronic obstructive pulmonary disease (COPD) and history of two or more flare-ups in the last 12 months and to study the influence of concomitant bronchiectasis on its effect.

Material/Methods: We prospectively observed 60 COPD patients with frequent exacerbations and predominantly severe disease (mean forced expiratory volume in 1 second [FEV1] - 44\%). Addition of six-month intermittent Azithromycin (500 mg three times weekly) to standard therapy was compared to standard therapy only in respect to exacerbation frequency and time to first exacerbation.

Results: Azithromycin, in comparison to standard therapy, led to a higher reduction of exacerbation frequency (-1.47 vs -0.87 events per patient-year) but did not affect hospitalization frequency (-0.57 vs. -0.53 events per patient-year). The time to first exacerbation was longer in the macrolide group (233 days) than in the control group (125 days) $(P=0.011)$. Bronchiectasis did not influence the effect of tested macrolide on exacerbations. No significant effect on lung function, symptoms, quality of life, physical capacity and sputum and throat swab microbiology was found.

Conclusions: Azithromycin reduced the frequency of exacerbations and delayed the time to first exacerbation. The effect was independent on the presence of bronchiectasis.

Keywords: chronic obstructive pulmonary disease, bronchiectasis, exacerbations, Azithromycin,

\section{INTRODUCTION:}

Long-term macrolides are used to reduce chronic obstructive pulmonary disease (COPD) exacerbations probably via reduction of bronchial inflammation, immunomodulation, affecting airway microorganisms [1]. COPD patients' groups that most effectively respond to this treatment are still unknown. Large trials have shown the beneficial effects of macrolides in bronchiectasis [2]. However, patients with concomitant bronchiectasis were often excluded from macrolide studies in COPD, or the presence of bronchiectasis has had not been evaluated [3, 4]. On the other hand, patients with COPD were excluded from macrolide studies in bronchiectasis [2].

It led us to assess the efficacy of Azithromycin on the prevalence of exacerbations and time to first exacerbation in COPD patients with a history of two or more flareups in the last 12 months (frequent exacerbators) and to evaluate the influence of concomitant bronchiectasis on its effect. As secondary endpoints treatment effect on sputum and throat swab microbiology, spirometry, symptoms, quality of life, physical capacity was measured.

\section{MATERIALS AND METHODS:}

It was a prospective observational (cohort) study on long-term macrolide treatment in COPD conducted in a university hospital. The study protocol was approved by the Institutional Ethical Committee. Diagnosis (forced expiratory volume in one second (FEV1)/forced vital capacity $(\mathrm{FVC})<70 \%)$ and severity assessment were based on Global Initiative for Chronic Obstructive Lung Disease (GOLD) criteria [5]. Eighty-three consecutive patients with frequent exacerbations (two or more in the previous year) treated in our clinic in 2015 were offered to participate in the study. All of them has had high resolution computed tomography (HRCT) done within the last three years to assess the presence of bronchiectasis. Those who had signed written consent form were included in the survey at least 28 days after the end of the last exacerbation and were divided into two groups. Azithromycin group (interventional group) was treated orally with Azithromycin $500 \mathrm{mg}$ tablets three times weekly (Monday, Wednesday and Friday) in addition to standard inhaled COPD therapy (Table 1) for a period of six months. The second group (control group) was treated with standard inhaled therapy only (Table 1). Recruitment stopped when both groups reached 30 patients. The allocation of patients to both groups was based on medical judgment.

Initially, electrocardiography (ECG) (Mortara ELI 150, Milwakee, Wisconsin, USA) was performed to determine the corrected QT (QTc) interval and evaluate the risk of arrhythmia. Patients with an extended QTc interval greater than $440 \mathrm{~ms}$ (defined by the Fridericia formula, where $\mathrm{QTcF}=\mathrm{QT} / \mathrm{RR}^{0.33}$ ) did not receive Azithromycin. 
Other exclusion criteria were the presence of serious comorbidity that limits patient's ability to participate or can influence the results (active malignant disease, severe heart or kidney failure, chronic liver disease, significant arrhythmia, active or non-active lung tuberculosis).

At enrolment and on the sixth month of treatment the following tests were performed: patient history; physical examination; post-bronchodilator spirometry (15 minutes after inhalation of $400 \mathrm{mg}$ salbutamol) according to ERS/ATS criteria [6] (Master Screen Body, CareFusion, Hoechberg, Germany); assessment of physical capacity (by the distance reached in six-minute walk test [6MWTD], validated by The American Thoracic Society [ATS] [7]), symptoms (COPD assessment test [CAT] and The Modified Medical Research Council Dyspnea Scale [mMRC]) and quality of life (QoL) (St. George's Respiratory Questionnaire [SGRQ]); measurement of systemic inflammation with $\tilde{N}$-reactive protein (CRP) (latex enhanced turbidimetry; ADVIA Chemistry, Siemens Healthineers; reference value $<5 \mathrm{mg} / \mathrm{L}$ ). Microbiological examination of throat swab for the pharyngeal carriage of Potentially Pathogenic Microorganisms (PPMs) was also done. It was followed by a microbiological examination of sputum samples (spontaneous or induced by inhalation of a $4.5 \%$ sodium chloride solution in accordance with a procedure recommended by a working group of European Respiratory Society [ERS]) [8]. The adequacy of the specimen was assessed microscopically ( $<10$ epithelial cells and $\geq 25$ leukocytes per low-power field). As a clinically significant result was reported any microbial count for Pseudomonas aeruginosa and $\geq 10^{3}$ Colony Forming Units per $\mathrm{ml}$ for another microbial species. Lack of sputum sampling was related to patients' inability to expectorate sputum spontaneously or after induction with hypertonic saline. Antimicrobial susceptibility testing by the Kirby-Bauer disc diffusion method was performed.

Exacerbations frequency and time to first exacerbation which were the primary outcomes were evaluated 12
$( \pm 1)$ months after the start of treatment. An exacerbation was defined as worsening in patient symptoms that require treatment with antibiotics and/or systemic corticosteroids (moderate) or hospital admission (severe) [5]. A new exacerbation is defined if symptoms occur at least 28 days after the end of the previous event [9].

Diagnosis of bronchiectasis was based on HRCT, and the modified Reiff Score was used to assess radiological severity [10]. It ranges one to 18 and includes the number of affected lung lobes (the lingual is considered as a separate lobe) and the degree of bronchial dilation (tubular $=1$, varicose $=2$, cystic $=3$ ). Risk of further exacerbations in bronchiectasis patients was measured by multidimensional bronchiectasis severity index (BSI) [11].

\section{STATISTICAL ANALYSIS:}

The quantitative variables were reported as mean and standard deviation (SD); qualitative variables were presented as number (n) and frequency (\%) of cases. T-test of Student and Paired-Samples T-test were used for comparison of two numerical variables. Proportions were compared with $\chi 2$-test (Fisher's exact test). Analysis of the proportion of patients free from COPD exacerbations within the year of follow up was performed by Kaplan-Meier curves. The $P$ value of less than 0.05 was considered statistically significant. The data were processed with SPSS Statistics for Windows, version 17 (SPSS, IBM, Chicago, IL, USA).

\section{RESULTS:}

The demographic characteristic of the interventional and the control groups was similar (Table 1). The average number of exacerbations for the previous year was 2.30 and 2.27, respectively. Risk of further exacerbations (assessed by BSI) in bronchiectasis patients from the two tested groups did not differ. Drugs used as baseline treatment were equivalent and not changed during the 12month observational period. There were no patients treated with theophylline.

Table 1. Patients' demographic at enrollment ( $P>0.05$ on each comparison).

\begin{tabular}{|l|l|l|l|}
\hline & Azithromycin group & Standard therapy group & $\boldsymbol{P}$ \\
\hline Males & $22(73.3 \%)$ & $23(76.7 \%)$ & 0.766 \\
\hline Age $($ years $)$ & $61.7 \pm 8.1$ & $65.3 \pm 7.1$ & 0.074 \\
\hline BMI $\left(\mathrm{kg} / \mathrm{m}^{2}\right)$ & $26.04 \pm 5.84$ & $26.25 \pm 5.58$ & 0.893 \\
\hline COPD duration (years) & $6.43 \pm 4.60$ & $5.47 \pm 5.19$ & 0.448 \\
\hline FVC (L and \% pred.) & $2.31 \pm 0.68 \mathrm{~L}(67.7 \pm 15.2 \%)$ & $2.35 \pm 0.72 \mathrm{~L} \mathrm{(65.6 \pm 18.3 \% )}$ & 0.787 \\
& & & 0.628 \\
\hline FEV1 (L and \% pred.) & $1.16 \pm 0.36 \mathrm{~L} \mathrm{(42.9 \pm 11.3 \% )}$ & $1.28 \pm 0.52 \mathrm{~L} \mathrm{(45.3 \pm 15.6 \% )}$ & 0.310 \\
& & & 0.506 \\
\hline GOLD stage & & & 0.287 \\
\hline$\bullet 2$ & $6(20.0 \%)$ & $10(33.3 \%)$ & \\
\hline$\bullet 3$ & $21(70.0 \%)$ & $15(50.0 \%)$ & \\
\hline$\bullet 4$ & $3(10.0 \%)$ & $5(16.7 \%)$ & 0.284 \\
\hline Bronchiectasis & $9(30.0 \%)$ & $13(43.3 \%)$ & 0.149 \\
\hline Reiff Score & $5.00 \pm 3.57$ & $3.29 \pm 1.94$ & \\
\hline
\end{tabular}




\begin{tabular}{|l|l|l|l|}
\hline BSI & $10.00 \pm 2.65$ & $10.64 \pm 3.48$ & 0.642 \\
\hline Smokers & & & 0.389 \\
\hline$\bullet$ current & $12(40.0 \%)$ & $17(56.7 \%)$ & \\
\hline$\bullet$ former & $14(46.7 \%)$ & $11(36.7 \%)$ & \\
\hline$\bullet$ never & $4(13.3 \%)$ & $2(6.7 \%)$ & \\
\hline Pack years & $38.9 \pm 22.2$ & $44.7 \pm 24.7$ & 0.383 \\
\hline Standard inhaled treatment & & & 0.587 \\
\hline$\bullet$ LAMA & $1(3.3 \%)$ & $1(3.3 \%)$ & \\
\hline$\bullet$ LABA & $3(10.0 \%)$ & $1(3.3 \%)$ & \\
\hline$\bullet$ LAMA+LABA & $5(16.7 \%)$ & $5(16.7 \%)$ & \\
\hline$\bullet$ LABA+ICS & $1(3.3 \%)$ & $4(13.3 \%)$ & \\
\hline$\bullet$ LAMA+LABA+ICS & $20(66.7 \%)$ & $19(63.4 \%)$ & \\
\hline
\end{tabular}

Patients receiving only standard COPD treatment had fewer symptoms (CAT difference - about 2 points), less affected quality of life (difference in SGRQ - about 2.7 points) and slightly better physical capacity (a difference of 16.3 meters on 6MWT) at the beginning of the study but without the statistical significance of these differences (Table 2).

Table 2. Baseline symptoms, quality of life and physical capacity ( $\mathrm{P}>0.05$ on each comparison).

\begin{tabular}{|l|l|l|l|}
\hline & Azithromycin group & Standard therapy group & $\boldsymbol{P}$ \\
\hline mMRC & $2.17 \pm 0.65$ & $2.13 \pm 0.78$ & 0.857 \\
\hline CAT & $25.47 \pm 8.27$ & $23.24 \pm 9.82$ & 0.344 \\
\hline SGRQ & $58.94 \pm 19.53$ & $56.27 \pm 19.15$ & 0.596 \\
\hline$\bullet$ symptoms & $70.35 \pm 18.70$ & $69.84 \pm 17.30$ & 0.912 \\
\hline - activities & $68.25 \pm 19.26$ & $60.68 \pm 22.85$ & 0.171 \\
\hline - impact & $50.16 \pm 23.38$ & $48.24 \pm 23.02$ & 0.750 \\
\hline 6MWTD (meters) & $357.0 \pm 100.6$ & $373.3 \pm 131.0$ & 0.591 \\
\hline
\end{tabular}

Azithromycin was the macrolide chosen for the purpose of the study because of its long half-life allowing intermittent use (three times weekly), as well as the good safety profile and the lack of significant drug interactions. Accompanying diseases requiring the use of a number of medications were diagnosed in $80 \%$ of the patients treated with a macrolide (cardio-vascular diseases - 20 patients, diabetes -7 patients) and $90 \%$ of the control group (cardio- vascular diseases -25 patients, diabetes -4 patients).

We found that both treatment regiments led to a significant decline of exacerbations and hospitalizations at the year of treatment in comparison to the previous year (Table 3). The effect of Azithromycin was associated with a higher reduction of the overall number of moderate and severe exacerbations than standard therapy, but no effect was observed on the hospitalizations (Figure 1).

Table 3. Frequency of exacerbations and hospitalizations at the years before and during the study.

\begin{tabular}{|l|l|l|l|}
\hline & $\begin{array}{l}\text { Azithromycin } \\
\text { group }\end{array}$ & $\begin{array}{l}\text { Standard therapy } \\
\text { group }\end{array}$ & $\begin{array}{l}\boldsymbol{P} \text { (between both } \\
\text { treatment regiments) }\end{array}$ \\
\hline Exacerbations & mean \pm SD & & \\
\hline$\bullet$ before & $2.30 \pm 0.79$ & $2.27 \pm 1.02$ & 0.888 \\
\hline$\bullet$ after & $0.83 \pm 0.83$ & $1.40 \pm 1.30$ & 0.049 \\
\hline $\boldsymbol{P}$ (before/after treatment) & 0.001 & 0.001 & \\
\hline Hospitalizations & & & \\
\hline$\bullet$ before & $1.10 \pm 1.09$ & $1.40 \pm 0.81$ & 0.233 \\
\hline$\bullet$ after & $0.53 \pm 0.82$ & $0.87 \pm 1.28$ & 0.234 \\
\hline $\boldsymbol{P}$ (before/after treatment) & 0.002 & 0.018 & \\
\hline
\end{tabular}


Fig. 1. Changes of exacerbations and hospitalizations frequencies during 12 months study period

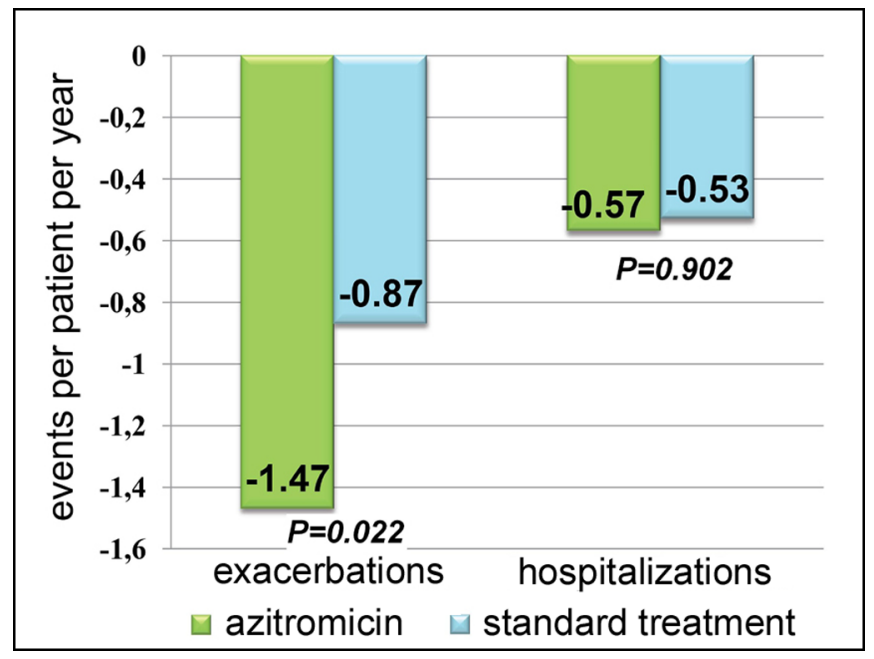

Presence of bronchiectasis did not influence the decline of exacerbation and hospitalization rates in treated with Azithromycin (Figure 2) although a significant drop of these events was seen within the tested groups (Table 4).
Fig. 2. Changes of exacerbations and hospitalizations frequencies in patients treated with Azithromycin depending on the presence of bronchiectasis during 12 months study period.

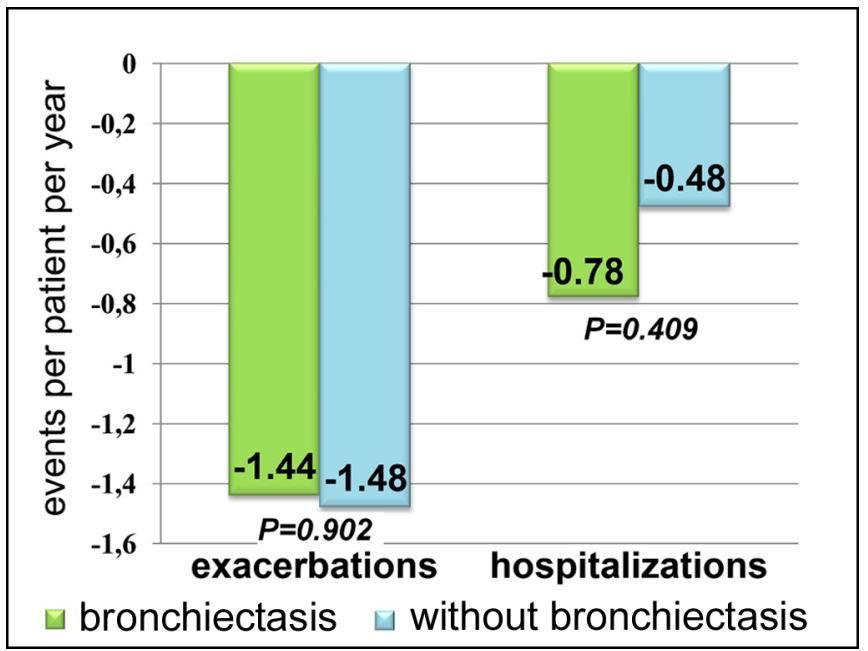

Table 4. Frequency of exacerbations and hospitalizations in patients treated with azithromycin depending on the presence of bronchiectasis at the years before and during the study.

\begin{tabular}{|c|l|l|l|}
\hline & $\begin{array}{l}\text { Bronchiectasis } \\
(\mathbf{n = 9})\end{array}$ & $\begin{array}{l}\text { Without bronchiectasis } \\
(\mathbf{n = 2 1})\end{array}$ & $\begin{array}{l}\boldsymbol{P} \text { (between both } \\
\text { treatment regiments) }\end{array}$ \\
\hline Exacerbations & mean \pm SD & \\
\hline$\bullet$ before & $2.44 \pm 0.88$ & $2.24 \pm 0.77$ & 0.524 \\
\hline$\bullet$ after & $1.00 \pm 0.71$ & $0.76 \pm 0.89$ & 0.483 \\
\hline $\boldsymbol{P}$ (before/after treatment) & $<0.001$ & $<0.001$ & \\
\hline Hospitalizations & \multicolumn{2}{|l|}{} \\
\hline$\bullet$ before & $1.44 \pm 1.42$ & $0.95 \pm 0.92$ & 0.266 \\
\hline$\bullet$ after & $0.67 \pm 0.87$ & $0.48 \pm 0.81$ & 0.569 \\
\hline $\boldsymbol{P}$ (before/after treatment) & 0.023 & 0.029 & \\
\hline
\end{tabular}

Kaplan-Meier analysis showed that the risk of acute COPD exacerbations was reduced in patients receiving Azithromycin (Figure 3). Time to first exacerbation was 108 days longer for those treated with Azithromycin in comparison to the control group (Table 5). Concomitant bronchiectasis did not significantly affect this period (Table 5). It is important to note that patients with bronchiectasis had an exacerbation earlier than those without - with 58 days in the macrolide and 61 days in the control group (Table 5).

Fig. 3. Kalpan-Meier analysis curve on the proportion of patients free from moderate or severe COPD exacerbations during one year of follow up. (Log Rang test; $\chi 2=4,934 ; P=0.026$ ).

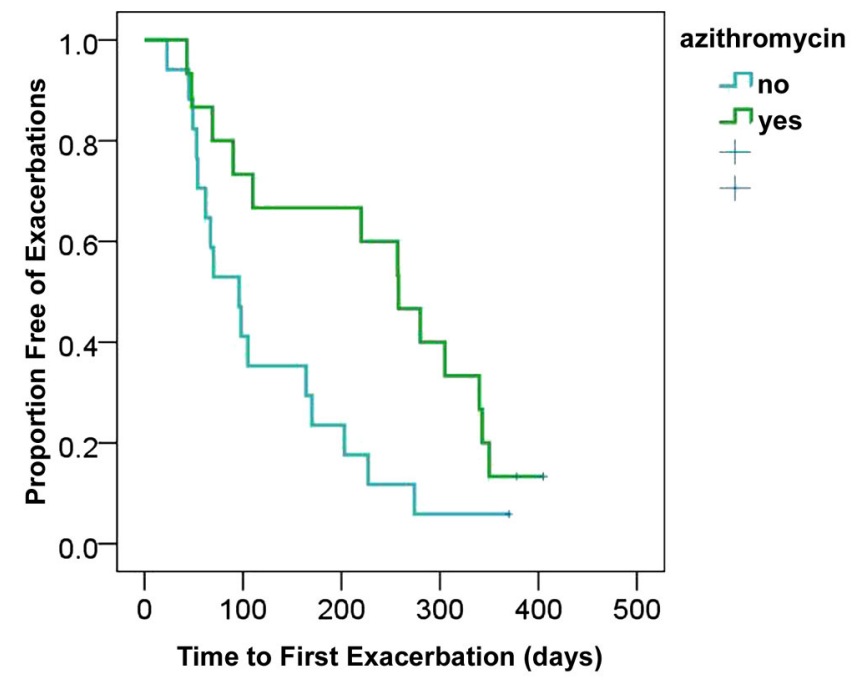


Table 5. Mean time to first moderate or severe exacerbation depending on presence of bronchiectasis.

\begin{tabular}{|c|l|l|c|c|}
\hline & $\begin{array}{l}\text { Azithromycin } \\
\text { group }\end{array}$ & $\begin{array}{l}\text { Standard } \\
\text { therapy group }\end{array}$ & $\begin{array}{c}\text { Mean difference } \\
\text { between treatment } \\
\text { groups (days) }\end{array}$ & 108 \\
\hline Time to first exacerbation (days) & $233 \pm 128$ & $125 \pm 96$ & 110 & 0.011 \\
\hline$\bullet$ With bronchiectasis & $194 \pm 129$ & $95 \pm 65$ & 104 & 0.075 \\
\hline$\bullet$ Without bronchiectasis & $252 \pm 130$ & $160 \pm 117$ & 0.135 \\
\hline
\end{tabular}

Symptoms, quality of life and physical capacity were not influenced by macrolide treatment (Table 6). Systemic inflammation measured by serum CRP level decreased more in the azithromycin group (-1.48 vs $0.43 \mathrm{mg} / \mathrm{L})$, but this difference was not significant (Table 6).

Table 6. Treatment effect on some parameters on sixth month of treatment ( $\mathrm{P}>0.05$ on each comparison).

\begin{tabular}{|l|c|c|c|}
\hline & Azithromycin group & Standard therapy group & $P$ \\
\hline$\Delta$ FVC $(\mathbf{m l})$ & $-(110 \pm 367)$ & $-(80 \pm 309)$ & 0.744 \\
\hline$\Delta$ FEV1 $(\mathbf{m l})$ & $-(40 \pm 202)$ & $-(40 \pm 181)$ & 0.989 \\
\hline$\Delta$ CAT & $-(0.57 \pm 7.23)$ & $-(0.37 \pm 5.36)$ & 0.909 \\
\hline$\Delta$ mMRC & $-(0.13 \pm 0.82)$ & $-(0.04 \pm 0.76)$ & 0.648 \\
\hline$\Delta$ SGRQ & $-(2.21 \pm 10.38)$ & $-(4.13 \pm 11.05)$ & 0.500 \\
\hline$\Delta$ CRP $(\mathbf{m g} / \mathbf{L})$ & $-(1.48 \pm 6.92)$ & $-(0.43 \pm 5.42)$ & 0.529 \\
\hline$\Delta$ 6MWD $(\mathbf{m})$ & $-(2.1 \pm 63.8)$ & $+(0.5 \pm 70.2)$ & 0.883 \\
\hline
\end{tabular}

$\Delta$ - six-month dynamic.

Pulmonary function parameters were slightly lower in patients in the interventional group (Table 1). After six months of treatment, we found a decrease of FEV1 by 40 $\mathrm{ml}$ in both groups and a decrease of FVC with $110 \mathrm{ml}$ in macrolide-treated patients versus $80 \mathrm{ml}$ in the control group $(P=$ non-significant $[\mathrm{NS}])$ (Table 6).

Ten patients from the two compared groups had PPMs in sputum samples before treatment, seven patients of Azithromycin and six patients of the control group had bron- chiectasis (Table 7). All the isolates were Gram negative (except one Enterococcus faecalis isolate) probably due to the severity of the disease. We did not find an effect of macrolide treatment on pathogenic microorganisms - on the sixth month Gram negative PPMs were again isolated in six patients on Azithromycin and two patients on standard treatment. Two patients had an emergence of new PPMs after treatment (K. pneumoniae in a macrolide therapy patient and $P$. aeruginosa in a standard therapy patient).

Table 7. Sputum microbiology.

\begin{tabular}{|l|c|c||c|c|}
\hline \multirow{2}{*}{} & \multicolumn{2}{|c||}{ Azithromycin group } & \multicolumn{2}{c|}{ Standard therapy group } \\
\cline { 2 - 5 } & At enrolment & At sixth month & At enrolment & At sixth month \\
\hline Pseudomonas aeruginosa & 6 & 4 & $3(1 \mathrm{MDR})$ & 2 \\
\hline Acinetobacter baumannii & - & 1 & 1 & 1 (ESBL) \\
\hline Escherichia coli & 1 & - & $2(1 \mathrm{ESBL})$ & - \\
\hline Klebsiella pneumoniae & - & 1 & 1 & 1 \\
\hline Stenotrophomonas maltophilia & 1 & - & - & - \\
\hline Enterococcus faecalis & 1 & - & 1 & - \\
\hline Proteus mirabilis & - & 1 & - & - \\
\hline Moraxella catarrhalis & - & $7(4 \mathrm{BE})$ & $10(6 \mathrm{BE})$ & $3(2 \mathrm{BE})$ \\
\hline Citrobacter freundii & $10(7 \mathrm{BE})$ & - & - \\
\hline All PPMs isolates & & & & - \\
\hline
\end{tabular}




\begin{tabular}{|l|c|c||c|c|}
\hline Candida spp. & 3 & 1 & 3 & 1 \\
\hline $\begin{array}{l}\text { No organisms isolated } \\
\text { (number of patients) }\end{array}$ & 15 & 19 & 15 & 22 \\
\hline $\begin{array}{l}\text { No sputum sampling } \\
\text { (number of patients) }\end{array}$ & 2 & 3 & 3 & 4 \\
\hline
\end{tabular}

MDR - multi drug resistant; ESBL - extended spectrum beta-lactamase; BE - bronchiectasis.

Four patients had the same microorganisms before and after treatment - three of them were treated with àzithromycin (positive for $P$. aeruginosa), and one was on standard therapy (positive for K. pneumoniae). The strains demonstrated the same antimicrobial susceptibility and no evidence of provoked resistance.
PPMs in throat swabs (Table 8) were isolated in $23.3 \%(n=7)$ in the macrolide group and $20 \%(n=6)$ in the control group at baseline. All of these patients had no PPM in the sixth month. In two patients on standard treatment, newly emerging Haemophilus influenzae and K. pneumoniae were found.

Table 8. Throat swab microbiology.

\begin{tabular}{|l|c|c||c|c|}
\hline \multirow{2}{*}{} & \multicolumn{2}{|c||}{ Azithromycin group } & \multicolumn{2}{c|}{ Standard therapy group } \\
\cline { 2 - 5 } & At enrolment & At sixth month & At enrolment & At sixth month \\
\hline Pseudomonas aeruginosa & 2 & - & - & - \\
\hline Haemophilus influenzae & - & - & - & 1 \\
\hline S. pneumoniae & - & - & 1 & - \\
\hline Escherichia coli & 1 & - & $2(1 \mathrm{ESBL})$ & - \\
\hline Klebsiella pneumoniae & 1 & - & - & 1 \\
\hline S. maltophillia & 1 & - & 1 & - \\
\hline Enterobacter cloacae & - & - & 1 & - \\
\hline Proteus mirabilis & - & - & - & - \\
\hline Staphylococcus aureus & 1 & - & - & - \\
\hline Burkholderia cepacia & 1 & - & $6(3 \mathrm{BE})$ & $2(1 \mathrm{BE})$ \\
\hline All isolates & $7(3 \mathrm{BE})$ & 0 & & - \\
\hline
\end{tabular}

ESBL - extended spectrum beta-lactamase; BE - bronchiectasis.

We observed clinically significant gastrointestinal bleeding and anemia in two patients - one of the control group and one after two weeks of azithromycin treatment. One patient in Azithromycin was affected by each of mild and fast reversible adverse effects - elevated liver enzymes, diarrhea, monomorphic ventricular extrasystoles, a transient decrease in hearing and vertigo.

Treatment with macrolide was discontinued in two patients. Three patients from the control group died during the observation.

\section{DISCUSSION:}

A meta-analysis of nine randomised controlled trials (RCTs) for the effect of macrolides on COPD exacerbations reveals the need of at least six to 12 months of azithromycin or erythromycin treatment to achieve an effect [12]. Three-month treatment with Azithromycin was found insufficient and showed only a tendency to delay the time to first exacerbation occurred [13]. In order to increase adherence to treatment and due to the fact that the greatest effect was observed during the first three to four months of treatment, a six-month treatment course was chosen for the current study.

At the time of enrolment in our research exacerbation frequency in both tested groups were 2.3 events per year and reached 0.83 events in the azithromycin group versus 1.40 in the control group at the year of intervention (decreasing of 1.47 vs 0.87 events respectively). Data of larger drop in exacerbations (4 events per patient-year) exists in the available literature, but it was seen in patients with a history of more previous exacerbations than in our population ( 6.8 per year in Pomares' trial [14] vs 2.3 in our trial). It suggests that the greatest benefit of macrolide treatment is expected in patients with more exacerbations [14]. Similar to our results were obtained from Uzun in which trial azithromycin reduced exacerbations with approximately one event per year in COPD patients with three or more exacerbations in the previous year [4]. There is a guess that Azithromycin is not effective in active smokers [15] which were $40 \%$ of our patients and may also affect the result. It is arguable if the degree of airway obstruction, which was severe in our tested population affects macrolide treatment [15]. 
Exacerbation delay with 108 days when treated with macrolide was higher than Albert's data of 92 days (266 vs 174 days in the active and control group respectively) after one year treatment [16]. According to the same trial [16], Azithromycin had no effect on the incidence of hospitalizations which is in concordance with our results - a drop of 0.5 events per patient per year $(\mathrm{P}=\mathrm{NS})$ regardless of the treatment applied (Azithromycin or placebo for 12 months). Treatment with erythromycin also resulted in a variety of outcomes - delayed exacerbation by 182 days in 12-month treatment and by 69 days in six-month treatment [17].

We did not find trials that take into account the macrolide effect on COPD exacerbations depending on the presence of bronchiectasis. Pomares estimated the existence of bronchiectasis $(58.4 \%$ of tested patients) but did not test azithromycin effect depending on the presence or absence of bronchiectasis [14].

Although macrolides show improvement in SGRQ, it is usually non-significant [3]. We found no effect of Azithromycin on the QoL, symptoms (CAT), dyspnea (mMRC) and the physical capacity of the studied patients. The latter was in contrast with a six-month erythromycin study [18]. We can speculate that longer treatment is required to affect these parameters, which are indirect effects of exacerbation frequency. In addition, this raises the issue of adverse reactions and microbial resistance, as well as the adherence of the patients to such therapy.

Macrolides show a large variation in respect to the eradication of respiratory pathogens according to two metaanalyses of studies in bronchiectasis. A significant effect on the clearance of $H$. influenzae and $M$. catarrhalis only was found [2, 19]. Macrolides reduced the chance of a new appearance of $M$. catarrhalis but not other microorganisms $[2,19]$. Our study did not show any effect on sputum microbiology in regard to the eradication or emergence of pathogens. Some changes in lung microflora cannot be detected by sputum cultures. Azithromycin administered for two months to current or former smokers with emphysema has had not alterd the bacterial load in bronchoalveolar lavage but has changed the quality of the lung microbiota and has affected some bacterial anti-inflammatory metabolites that may contribute to its therapeutic effect [20].

Data on macrolides effect on bacterial resistance also fluctuates. In some trials, the microbial profile of sputum isolates has not been affected by erythromycin or Azithromycin [2, 12]. There were no newly emerging multiresistant Gram negative strains among patients treated with ñlarithromycin [3]. Increased macrolide resistance in nasopharyngeal streptococci (81\% of those treated with Azithromycin and $41 \%$ in the placebo group) and PPMs in sputum $(88 \%$ in macrolide versus $26 \%$ in the placebo group) were also described [17]. In contrast, Uzun reported macrolide resistant sputum bacteria in $6 \%$ of the azithromycin group and $24 \%$ of the placebo group [4]. Our analysis on bacterial resistance in sputum was based only on three isolates of $P$. aeruginosa and cannot serve as a refer- ence but showed any provoked resistance after six months of treatment with azithromycin.

According to the literature, only diarrhea [4] and hearing loss [16] were more common adverse effects in macrolide groups in comparison to placebo. A meta-analysis of six RCTs found a tendency of increased adverse reactions and reduced mortality (by $15 \%$ ) in macrolide groups, but it was not statistically significant [21]. We also observed more side effects in the macrolide group - two of them led to treatment discontinuation - gastrointestinal bleeding in one patient (doctor's decision to stop the therapy) and slightly elevated liver enzymes during exacerbation (patient's withdrawal).

Our study has several limitations - it was a singlecentre study; the tested groups were relatively small and not randomized. There was no placebo drug, and patients knew that were treated with additional medicine, which actually is a real clinical practice. There were no spirometry, microbiology, symptoms and QoL tests on the 12th month when was the end of the follow-up period in regard to exacerbation frequencies.

\section{CONCLUSION:}

Azithromycin reduced the frequency of exacerbations and delayed the time to first exacerbation without significant effect on lung function, symptoms, quality of life, physical capacity and sputum and throat swab microbiology. Concomitant bronchiectasis did not impact macrolide's effect on exacerbations.

\section{Abbreviation list:}

ATS - The American Thoracic Society

BE - bronchiectasis

BMI - body mass index

BSI - bronchiectasis severity index

CAT - COPD assessment test

CRP - C-reactive protein

ECG - electrocardiography

ERS - European Respiratory Society

ESBL - extended spectrum beta-lactamase

FEV1 - forced expiratory volume in one second

FVC - forced vital capacity

GOLD - Global Initiative for Chronic Obstructive Lung Disease

HRCT - high resolution computed tomography

ICS - inhaled corticosteroid

LAMA - long-acting muscarinic antagonist

LABA - long-acting beta-agonist

MDR - multi drug resistant

mMRC - The Modified Medical Research Council

Dyspnea Scale

NS - non-significant

PPMs - Potentially Pathogenic Microorganisms

QoL - Quality of Life

RCTs - randomised controlled trials

SGRQ - St. George's Respiratory Questionnaire

6MWTD - six minute walking test distance 


\section{REFERENCES:}

1. Santos S, Marin A, Serra-Batlles J, de la Rosa D, Solanes I, Pomares X, et al. Treatment of patients with COPD and recurrent exacerbations: the role of infection and inflammation. Int $J$ Chron Obstruct Pulmon Dis. 2016; 11(1):515-525. [PubMed] [Crossref]

2. Fan LC, Lu HW, Wei P, Ji XB, Liang $\mathrm{S}, \mathrm{Xu}$ JF. Effects of long-term use of macrolides in patients with noncystic fibrosis bronchiectasis: a metaanalysis of randomized controlled trials. BMC Infect Dis. 2015 Mar 27; 15(1):160. [PubMed] [Crossref]

3. Cui Y, Luo L, Li C, Chen P, Chen Y. Long-term macrolide treatment for the prevention of acute exacerbations in COPD: a systematic review and metaanalysis. Int J Chron Obstruct Pulmon Dis. 2018 Nov;13:3813-3829. [PubMed] [Crossref]

4. Uzun S, Djamin RS, Kluytmans J, Mulder PJ, van't Veer NE, Ermenes AA, et al. Azithromycin maintenance treatment in patients with frequent exacerbations of chronic obstructive pulmonary disease (COLUMBUS): a randomised, double-blind, placebocontrolled trial. The Lancet. 2014; 2(5):361-368. [PubMed] [Crossref]

5. Global Strategy for the Diagnosis, Management and Prevention of Chronic Obstructive Pulmonary Disease, Global Initiative for Chronic Obstructive Lung Disease (GOLD). 2014. [nternet]

6. Miller MR, Hankinson J, Brusasco V, F. Burgos, R. Casaburi, A. Coates, et al. Standardisation of spirometry. Eur Respir J. 2005; 26(2):319-338. [PubMed] [Crossref]

7. ATS Statement: Guidelines for the Six-Minute Walk Test. Am J Respir Crit Care Med. 2002;166(1):111-117. [PubMed] [Crossref]

8. Paggiaro PL, Chanez P, Holz O, Ind P, Djukanovic R, Maestrelli P, et al.
Sputum induction - Report of working group 1. Eur Respir J. 2002; 20: 3-8.

9. Burge S, Wedzicha JA. COPD exacerbations: definitions and classifications. Eur Respir J. 2003 Jun;21:4653. [PubMed] [Crossref]

10. Reiff DB, Wells AU, Carr DH, Cole PJ, Hansell DM. CT findings in bronchiectasis: limited value in distinguishing between idiopathic and specific types. Am J Radiol. 1995 Aug; 165(2):261-267. [PubMed] [Crossref]

11. Chalmers JD, Goeminne P, Aliberti S, McDonnell MJ, Lonni S, Davidson J, et al. The Bronchiectasis Severity Index: an international derivation and validation study. Am J Respir Crit Care Med. 2014 Mar;189(5):576585. [PubMed] [Crossref]

12. Ni W, Shao X, Cai X, Wei C, Cui J, Wang R, et al. Prophylactic Use of Macrolide Antibiotics for the Prevention of Chronic Obstructive Pulmonary Disease Exacerbation: A Meta-Analysis. PLoS One. 2015 Mar 26; 10(3):e0121257. [PubMed] [Crossref]

13. Berkhof FF, Doornewaard-ten Hertog NE, Uil SM, Kerstjens HA, van den Berg JM. Azithromycin and coughspecific health status in patients with chronic obstructive pulmonary disease and chronic cough: a randomised controlled trial. Respiratory Research. 2013 Nov 14;14(1):125. [PubMed] [Crossref]

14. Pomares X, Montón C, Espasa M, Casabon J, Monsó E, Gallego M. Long-term azitromycin therapy in patients with severe COPD and repeated exacerbations. Int $J$ Chron Obstr Pulmon Dis. 2011 Sep 6;6:449-56. [PubMed] [Crossref]

15. Han MK, Tayob N, Murray S, Dransfield MT, Washko G, Scanlon PD, et al. Predictors of chronic obstructive pulmonary disease exacerbation reduction in response to daily azithromycin therapy. Am J Respir Crit Care. Med 2014 Jun 15;189(12):1503-8. [PubMed] [Crossref]

16. Albert RK, Connett J, Bailey WC, Casaburi R, Cooper JA Jr, Criner GJ, et al. Azithromycin for prevention of exacerbations of COPD. $N$ Engl J Med. 2011;365(8):689-98. [PubMed]

17. He ZY, Ou LM, Zhang JQ, Bai J, Liu GN, Li MH, et al. Effect of 6 Months of Erythromycin Treatment on Inflammatory Cells in Induced Sputum and Exacerbations in Chronic Obstructive Pulmonary Disease. Respiration. 2010; 80(6):445-452. [PubMed] [Crossref]

18. Tan C, Huang H, Zhang J, He Z, Zhong X, Bai J. Effects of Low-Dose and Long-Term Treatment With Erythromycin on Interleukin-17 and Interleukin-23 in Peripheral Blood and Induced Sputum in Patients With Stable Chronic Obstructive Pulmonary Disease. Mediators Inflamm. 2016; 2016:4173962. [PubMed] [Crossref]

19. Wu Q, Shen W, Cheng H, Zhou $\mathrm{X}$. Long-term macrolides for non-cystic fibrosis bronchiectasis: A systematic review and meta-analysis. Respirology. 2014 Apr;19(3):321-329. [PubMed] [Crossref]

20. Segal LN, Clemente JC, Wu BG, Wikoff WR, Gao Z, Li Y, et al. Randomised, double-blind, placebocontrolled trial with Azithromycin selects for anti-inflammatory microbial metabolites in the emphysematous lung. Thorax. 2017 Jan;72(1):13-22. [PubMed] [Crossref]

21. Donath E, Chauthry A, Hernandez-Aya LF, Lit L. A meta-analysis on the prophylactic use of macrolide antibiotics for the prevention of disease exacerbations in patients with Chronic Obstructive Pulmonary Disease. Respir med. 2013 Sep;107(9):1385-1392. [PubMed] [Crossref]

Please cite this article as: Kostadinova V, Radkov Y, Stoeva T, Miteva D. Long-term azithromycin treatment in chronic obstructive pulmonary disease. J of IMAB. 2020 Jul-Sep;26(3):3259-3266. DOI: https://doi.org/10.5272/jimab.2020263.3259

\section{Corresponding Author:}

Vanya K. Stefanova, Clinic of pulmonary diseases, UMHAT “St. Marina”,

1, Hristo Smirnenski Blvd., Varna 9000, Bulgaria,

E-mail: v_vanqkostadinova@abv.bg 